\section{BMJ Open} Ophthalmology

\title{
Dexamethasone intracameral drug- delivery suspension for inflammation associated with vitreoretinal surgery
}

\author{
Daniel F Kiernan (1D ${ }^{1,2}$
}

To cite: Kiernan DF. Dexamethasone intracameral drug-delivery suspension for inflammation associated with vitreoretinal surgery. BMJ Open Ophthalmology 2020;5:e000491. doi:10.1136/ bmjophth-2020-000491

Received 14 April 2020 Accepted 19 April 2020
Check for updates

C Author(s) (or their employer(s)) 2020. Re-use permitted under CC BY-NC. No commercial re-use. See rights and permissions. Published by BMJ.

${ }^{1}$ Ophthalmology, Ophthalmic Consultants of Long Island, Rockville Centre, New York, USA ${ }^{2}$ Department of Ophthalmology, Winthrop-University Hospital, Mineola, New York, USA

Correspondence to Dr Daniel F Kiernan; dkiernan@ ocli.net

\section{ABSTRACT}

Objective To evaluate the efficacy of an anterior chamber intracameral dexamethasone (ICD) drugdelivery suspension (Dexycu; EyePoint Pharmaceuticals, Watertown, Massachusetts, USA) providing sustained release of medication following a single application for the treatment of postoperative inflammation in patients undergoing vitreoretinal surgery compared to daily postoperative treatment with topical corticosteroids for up to 1 month.

Methods and analysis Retrospective case-matched comparison of patients undergoing initial vitreoretinal surgery by a single surgeon. Patients had a preoperative best-corrected visual acuity of 20/20 to light perception and a variety of vitreoretinal pathologies. 27 eyes of 27 patients received ICD at the time of surgery and were compared with 27 eyes of 27 patients who received daily postoperative corticosteroid eye drops over 4 weeks. The primary efficacy outcome was anterior chamber cell (ACC) clearing ( 0 cells) in the study eye at postoperative day (POD) 7. Ocular adverse events were assessed through POD 90.

Results ACC clearing at POD 7 was achieved in 67\% of eyes in the ICD treatment group and $37 \%$ of eyes in the control group treated with topical corticosteroids $(p=0.029)$. No serious ocular adverse events were noted up to POD 90 in either group.

Conclusion The ICD drug-delivery suspension placed in the anterior chamber after vitreoretinal surgery was more effective than topical corticosteroids in treating inflammation occurring 1 week following vitreoretinal surgery and thus may be an alternative to daily corticosteroid drop installation in this patient population.

\section{INTRODUCTION}

In the 50 years since it was first described, vitrectomy has become the third most frequently performed ophthalmic surgery in the USA. ${ }^{1}$ Despite a variety of technological advances, including smaller gauge instruments, higher frequency vitreous cutters and better adjunctive agents, these surgeries can still trigger a classic postoperative intraocular inflammatory response. ${ }^{2}$ Using a laser flare metre (LFM), Agarwal et al demonstrated that 25-gauge pars plana vitrectomy (PPV) procedures frequently resulted in increased anterior chamber flare presumed to be the

\section{Key messages}

What is already known about this subject?

> The intracameral dexamethasone drug-delivery suspension placed in the anterior chamber after cataract surgery has previously been shown to significantly reduce inflammation compared with placebo.

\section{What are the new findings?}

$\checkmark$ In this retrospective case-matched comparison of patients undergoing vitreoretinal surgery, we demonstrate that intracameral dexamethasone was more effective than topical corticosteroids at reducing inflammation postoperatively.

How might these results change the focus of research or clinical practice?

Treatment of postoperative inflammation with this intracameral dexamethasone suspension may offer clinical benefits to retinal surgeons and their patients.

result of increased vascular permeability and a break down in the blood-ocular barrier caused by inflammation. ${ }^{3}$

Although there is no established standard of care for the patient postoperative PPV, topical ophthalmic antibiotics, cycloplegics and anti-inflammatory drops are frequently prescribed. A survey of 41 retinal specialists indicated that $98 \%$ of them routinely prescribed topical corticosteroid drops following surgery. ${ }^{4}$

Shorstein and Myers recently described the growing trend towards the use of postoperative ophthalmic treatments following cataract surgery, including anti-inflammatory treatments, intended to replace the need for topical eyedrops. ${ }^{5}$ One such treatment is an intracameral injection of a dexamethasone suspension formulated to form a drug encapsulating sphere in the anterior chamber that degrades and releases the drug, treating postoperative inflammation, over the course of 30 days. The FDA approved this drug (Dexycu; Eyepoint Pharmaceuticals, Watertown, Massachusetts, USA) in 2018. 
The purpose of this retrospective chart review was to compare postoperative anterior chamber inflammation and safety outcomes in a group of patients who underwent PPV treated with intracameral dexamethasone (ICD) and matched group of controls treated with topical ophthalmic corticosteroids.

\section{METHODS}

\section{Study design}

This was a retrospective case-matched chart review conducted at a multilocation practice in New York, USA. Data were collected from patients undergoing initial vitreoretinal surgery by a single surgeon (DFK). The study protocol was granted an exemption by the Institutional Review Board due to its retrospective nature (Advarra, Columbia, Maryland, USA). Patients or the public were not involved in the design, or conduct, or reporting or dissemination plans of our research.

The test population included consecutive cases for 27 eyes of 27 patients who received ICD at the time of vitreoretinal surgery between April and September 2019. The outcomes were compared with those from 27 eyes of 27 patients who had surgery between January 2018 and May 2019, matched for age, gender and diagnosis, who were treated with daily postoperative corticosteroid eye drops over 4 weeks. Standard instructions for patients receiving topical corticosteroids were to apply 1 drop four times per day for 2 weeks and then 1 drop two times per day for the following 2 weeks. In order to provided uniformity, only patients treated with topical generic prednisolone acetate (Sandoz Inc, Princeton, New Jersey, USA) were included. No patients treated with ICD were prescribed topical postoperative ophthalmic corticosteroids.

All patients were assessed by the treating physician preoperatively, on postoperative day (POD) 1 and approximately on PODs 7, 30 and 90. All patients completed at least 90 days of postoperative assessments. Demographic data and case details about the patients' condition necessitating surgery were collected from the preoperative visit (day 0, baseline). Topical ophthalmic medications used and postoperative inflammation were recorded for PODs 1, 7, 30 and 90. Ocular adverse events (AEs) were assessed through POD 90. The primary efficacy outcome was the rate of anterior chamber cell (ACG) clearing (no ACCs) in the study eye at POD 7.

\section{Patients}

Male or female patients who had undergone unilateral vitreoretinal surgery were considered for inclusion in this trial. Patients who had any previous history of vitrectomy or posterior segment surgery were excluded. Other exclusion criteria included the following: use of any topical ophthalmic, or oral corticosteroid within 7 days before POD 0; receipt of a periocular or subconjunctival corticosteroid injection in the study eye in the 3 months before POD 0 or at the time of surgery; any history of intravitreal corticosteroid delivery vehicle (eg, Retisert; Bausch \& Lomb Incorporated, Bridgewater, New Jersey,
USA; Ozurdex; Allergan Inc, Irvine, California, USA; Iluvien; Alimera Sciences Inc, Alpharetta, Georgia, USA) in the study eye at any time; or use of topical ophthalmic nonsteroidal anti-inflammatory drugs (NSAIDs) in the study eye within 15 days before day 0 .

\section{Procedure}

All patients underwent 25-gauge PPV surgery using the Constellation Vision System (Alcon Laboratories, Fort Worth, Texas, USA). None of the cases required use of triamcinolone acetonide for visualisation. All cases and controls were first time vitrectomies and the surgeries were completed in under 1 hour. At the conclusion of vitreoretinal surgery for the test cases, the surgeon created a corneal paracentesis using a $15^{\circ}$ blade and injected the dexamethasone suspension as a single $5 \mu \mathrm{L}$ droplet by intracameral injection into the anterior chamber using a 28-gauge cannula. The ophthalmic surgeon monitored the status and placement of the drug delivery. The control groups were prescribed topical prednisolone acetate and did not receive any intracameral injection at the end of surgery. All patients received topical moxifloxacin $0.5 \%$ (Lupin Pharmaceuticals, Baltimore, Maryland, USA) four times per day for 1 week starting POD 1. No cycloplegics or topical NSAIDs were prescribed for any patient postoperatively.

\section{Analysis}

The primary endpoint was the proportion of study eyes with complete clearance of ACCs ( 0 cells $)$ at POD 7. All summaries and analyses were done for study eyes only. The rates of patients meeting the primary efficacy outcome in the study and control groups were compared using a $\chi^{2}$ analysis (SPSS V.26, IBM, Armonk, New York, USA) with $\alpha \leq 0.05$ considered statistically significant. Safety was assessed by recording AEs, intraocular pressure (IOP), visual acuity and other eye examination outcomes up to POD 90. At each study visit, patients were asked questions about symptoms in order to elicit complaints that would be considered AEs.

\section{RESULTS}

A total of 27 cases and 27 controls ( 54 eyes of 54 patients) were included in the retrospective analysis. Patients had a preoperative best-corrected visual acuity of $20 / 20$ to light perception and a variety of vitreoretinal pathologies (table 1). Age, gender and surgical eye as well as the conditions requiring surgical intervention were well matched in the case and control groups (tables 1 and 2).

\section{Primary efficacy end point}

The primary end point was the proportion of patients with complete ACC clearing in the study eye at POD 7. The ICD group showed significantly $(p=0.029)$ greater ACC clearing at POD 7 compared with the control group. ACC clearing at POD 7 was observed in $18(66.7 \%) / 27$ eyes treated with ICD and $10(37.0 \%) / 27$ of those treated with topical ophthalmic corticosteroids (figure 1). No 


\begin{tabular}{llll} 
Table 1 & Diagnosis and procedures performed & \\
\hline Procedure & Diagnosis & ICD (n=27) & $\begin{array}{l}\text { Control } \\
\text { (n=27) }\end{array}$ \\
\hline PPV EL & $\begin{array}{l}\text { VH; PDR, } \\
\text { RVO or RT }\end{array}$ & 10 & 10 \\
\hline PPV MP & ERM & 9 & 9 \\
$\begin{array}{l}\text { PPV MP AFX } \\
\text { gas }\end{array}$ & Macular hole & 4 & 4 \\
$\begin{array}{l}\text { PPV EL RD } \\
\text { repair AFX gas }\end{array}$ & RRD & 2 & 2 \\
$\begin{array}{l}\text { PPV TRD } \\
\text { repair }\end{array}$ & TRD PDR & 2 & 2 \\
\hline
\end{tabular}

AFX, Air fluid exchange; EL, endolaser; ERM, epiretinal membrane; ICD, intracameral dexamethasone; MP, membrane peel; PDR, proliferative diabetic retinopathy; PPV, pars plana vitrectomy; RD, retinal detachment; RRD, rhegmatogenous retinal detachment; $\mathrm{RT}$, retinal tear; RVO, retinal vein occlusion; TRD, tractional retinal detachment; $\mathrm{VH}$, vitreous haemorrhage.

eyes in the ICD group had anterior chamber inflammation requiring rescue medication on $\mathrm{POD} 1,7,30$ or 90.

\section{Secondary efficacy end points}

Secondary end points were defined as complete ACC clearing rates evaluated at follow-up visits on PODs 1 , 30 and 90 using the same criteria as the primary end point. Eyes treated with ICD had no cells in the anterior chamber at rates of $44.4 \%$ on POD $1,66.7 \%$ at the primary endpoint POD 7 visit, further increasing to $85.1 \%$ by POD $30 \%$ and $92.5 \%$ by POD 90 (figure 2). In the group treated with topical ophthalmic corticosteroids, an anterior clear of cells was observed in $22.2 \%$ of eyes at POD 1 , and $37.0 \%$ at POD 7 , further increasing to $74.0 \%$ by POD $30 \%$ and $81.4 \%$ by POD 90 . The difference between test and control treatment groups was significant after POD $1(\mathrm{p}=0.011)$ and POD $7(\mathrm{p}=0.029)$, but not significant $(p>0.05)$ at PODs 30 and 90.

\section{Safety outcomes}

Fewer patients treated with ICD $(12,44.4 \%)$ reported any AEs up to POD 90 compared with the controls (19, $70.3 \%$; table 3). An increase in IOP from baseline of any amount was recorded in $17(62.9 \%)$ patients in the test group, and $18(66.6 \%)$ in the control group but the

\begin{tabular}{lll}
\hline Table 2 & Patientdemographics and baseline characteristics \\
\hline & ICD (n=27) & $\begin{array}{l}\text { Control } \\
(\mathbf{n}=\mathbf{2 7})\end{array}$ \\
\hline Age (years), mean (SD) & $67.6(8.7)$ & $66.8(12.4)$ \\
$\begin{array}{l}\text { 265, n (\%) } \\
\text { Male gender, n (\%) }\end{array}$ & $21(77.7)$ & $19(70.3)$ \\
$\begin{array}{l}\text { Study eye, n (\%) } \\
\quad \text { Right }\end{array}$ & $15(55.5)$ & $14(51.8)$ \\
$\quad$ Left & $12(44.5)$ & $16(59.2)$ \\
\hline
\end{tabular}

ICD, intracameral dexamethasone.

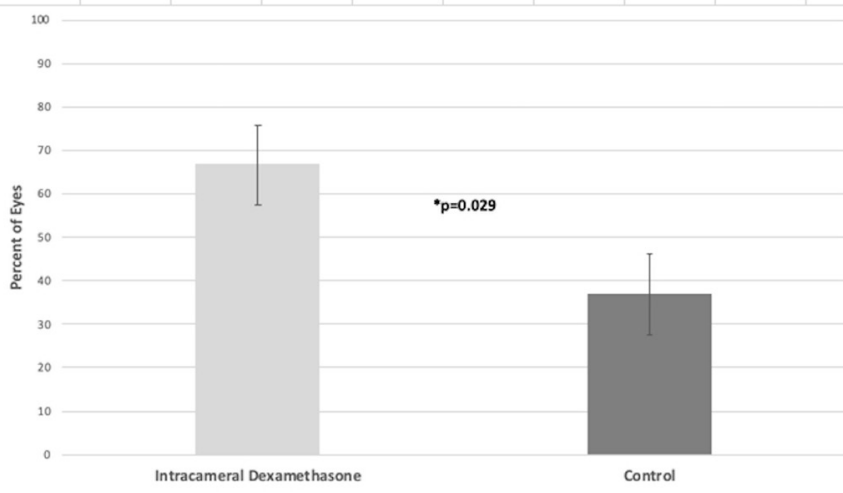

Figure 1 Bar graph showing primary end point: percentage of patients with ACC grade of 0 at POD 7. ACC, anterior chamber cell; POD, postoperative day.

mean IOP did not exceed $21 \mathrm{~mm} \mathrm{Hg}$ in any treatment group at any visit (table 4). An IOP increase of $10 \mathrm{~mm} \mathrm{Hg}$ or more from baseline to any time point up to POD 90 was observed in $2(7.4 \%)$ patients treated with ICD and 3 $(11.1 \%)$ patients in control group. Cataract progression in phakic eyes was common, $33 \%$ in the ICD and $75 \%$ in the control group, and one eye in the control group required surgery prior to POD 90. Other treatmentemergent AEs reported in at least $10 \%$ of eyes in either group were eye pain, foreign body sensation, vitreous floaters, corneal oedema and cystoid macular oedema (CME) (table 3).

\section{DISCUSSION}

Ophthalmic corticosteroids elicit numerous potent antiinflammatory effects and are a standard of care for the management of ocular inflammation. This retrospective pilot study was designed to assess the safety and efficacy of a novel ICD drug-delivery suspension for treating intraocular inflammation following a variety of posterior segment surgeries involving PPV. This analysis found that study eyes in the test group treated with ICD at the conclusion of the surgery were more likely to have complete clearing of anterior chamber inflammatory cells at POD 7 than study eyes of case-matched control patients treated

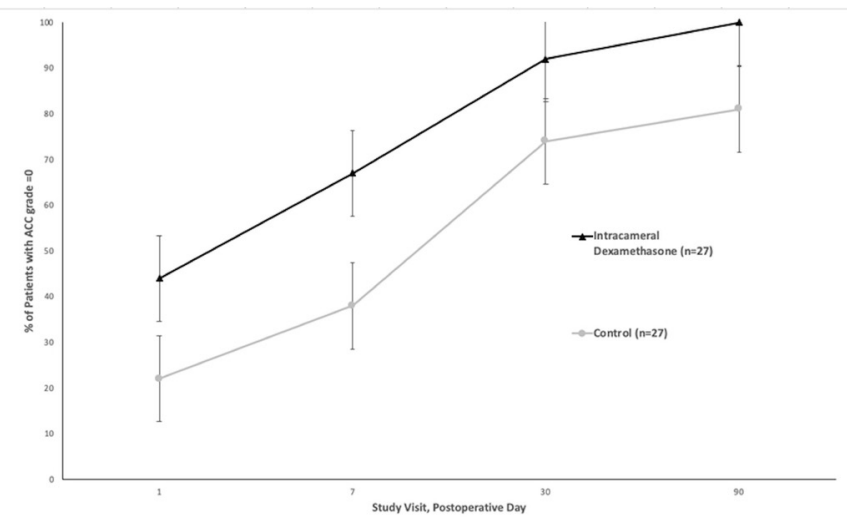

Figure 2 Proportion of patients with no evidence of ACCs ( $\pm 95 \% \mathrm{Cls})$. differences at day 1 and day 7 were statistically significant, $p<0.05$. ACCs, anterior chamber cells. 
Table 3 AEs occurring in $2 \%$ of patients in either group

ICD ( $\mathbf{n = 2 7 )}$

Control $(n=27)$

\begin{tabular}{|c|c|c|}
\hline $\begin{array}{l}\text { Any AE reported in study } \\
\text { eye }\end{array}$ & $12(44.4 \%)$ & $19(70.3 \%)$ \\
\hline Eye pain & 5 (18.5\%) & $5(18.5 \%)$ \\
\hline Foreign body sensation & $5(18.5 \%)$ & $3(11.1 \%)$ \\
\hline $\begin{array}{l}\text { Myodysopsia (vitreous } \\
\text { floaters) }\end{array}$ & $3(11.1 \%)$ & $5(18.5 \%)$ \\
\hline Dry eye & $1(3.7 \%)$ & $0(0.0 \%)$ \\
\hline Corneal oedema & $3(11.1 \%)$ & $1(3.7 \%)$ \\
\hline $\begin{array}{l}\text { Posterior capsule } \\
\text { opacification }\end{array}$ & $1(3.7 \%)$ & $2(7.4 \%)$ \\
\hline Macular oedema & $0(0.0 \%)$ & $2(7.4 \%)$ \\
\hline Cystoid macular oedema* & $1(3.7 \%)$ & $5(18.5 \%)$ \\
\hline $\begin{array}{l}\text { Increase in IOP } \geq 10 \mathrm{~mm} \\
\mathrm{Hg} \text { between PODs } 1 \text { and } \\
90\end{array}$ & $2(7.4 \%)$ & $3(11.1 \%)$ \\
\hline $\begin{array}{l}\text { Cataract progression in } \\
\text { patients with phakic eyes }\end{array}$ & $4 / 12(33.3 \%)$ & $12 / 16(75.0 \%)$ \\
\hline $\begin{array}{l}\text { Cataract surgery } \\
\text { performed in patients with } \\
\text { phakic eyes }\end{array}$ & 0/12 (0.0\%) & $1 / 16(6.2 \%)$ \\
\hline
\end{tabular}

*As determined by optical coherence tomography.

AEs, adverse events; ICD, intracameral dexamethasone; IOP, intraocular pressure; PODs, postoperative days.

with topical ophthalmic prednisolone acetate. Complete clearing of ACC at POD 7 was observed in $66.7 \%$ of test patents and $37.0 \%$ of the matched controls, $\mathrm{p} \leq 0.05$.

The improved control of postoperative intraocular inflammation in the ICD test group was observed as early as POD 1. Twelve of the $27(44.4 \%)$ eyes treated with ICD had no ACCs on the first PODversus 6 (22.2\%) of the 27 eyes treated topically with corticosteroid drops, $\mathrm{p} \leq 0.05$. The differences in anterior chambers free of inflammatory cells were no longer significant at days 30 and 90 .

Agarwal et al used a LFM to determine the level of anterior chamber inflammation in 50 eyes for 30 days following 25-gauge vitrectomy surgery. They reported that $22(44 \%)$ out of 50 patients had sufficient anterior chamber flare $(\geq 50$ photons $/ \mathrm{ms})$ to warrant treatment

\begin{tabular}{|c|c|c|c|c|}
\hline & \multicolumn{2}{|c|}{ ICD (n=27) } & \multicolumn{2}{|c|}{$\begin{array}{l}\text { Control } \\
(n=27)\end{array}$} \\
\hline & $\begin{array}{l}\text { Mean }(\mathrm{mm} \\
\mathrm{Hg})\end{array}$ & Range & $\begin{array}{l}\text { Mean }(\mathrm{mm} \\
\mathrm{Hg})\end{array}$ & Range \\
\hline Preoperative & 15.9 & $8-25$ & 16.3 & $11-24$ \\
\hline POD 1 & 13.4 & $7-19$ & 13.5 & $6-21$ \\
\hline POD 7 & 15.5 & $11-24$ & 16.9 & $11-28$ \\
\hline POD 30 & 15.4 & $9-24$ & 16.5 & $9-28$ \\
\hline POD 90 & 15.8 & $11-21$ & 16.4 & $7-25$ \\
\hline
\end{tabular}

$I C D$, intracameral dexamethasone; POD, postoperative day. with topical corticosteroids, which successfully returned the flare to preoperative levels. Multivariate analysis suggested that patients with higher preoperative anterior chamber flare, and men, were most likely to reach this threshold. No other variables were predictive of patients who would experience this level of postoperative inflammation.

The lower rate of anterior chamber inflammation reported in the aforementioned study compared with the present study may have several explanations. Agarwal et al reported rates of clinically significant inflammation, defined as LFM measurements $\geq 50$ photons/ms, while the present study reported rates of any inflammation, defined as greater than 0 ACCs. Additionally, triamcinolone acetonide was used as a visualising agent in nearly half of the eyes in the Agarwal study, whereas it was not used during surgery performed in the present study.

Supporting the notion of a depot approach to perioperative steroid treatment, a 2007 study by Paccola et al randomised 40 patients to treatment with either topical prednisolone acetate or subtenons triamcinolone acetate following 20-gauge PPV. This study found that there was no difference in the severity of ACC and flare, or other signs and symptoms of ocular inflammation, between the two treatments. ${ }^{6}$ The current study used ICD in a much smaller volume to achieve similar clinical efficacy.

The topical corticosteroid, $0.1 \%$ betamethasone, was compared with $0.1 \%$ diclofenac, a topical NSAID, for the treatment of postoperative inflammation in 200 patients who had combined cataract and 25-gauge vitreoretinal surgery. Although there were no overall differences in the severity of postoperative inflammation, eyes treated with the steroid were less impacted by the length of the surgery than eyes treated with the NSAID. This study also found that patients being treated for macular holes and epiretinal membranes had more IOP elevation in the betamethasone group. ${ }^{7}$ In the current study, we did not observe a difference in inflammation rates or severity between different indications for primary vitrectomy surgery, although the exact duration of each case was not recorded and topical NSAIDs were not prescribed to any patient.

Postoperative IOP elevation is a known complication of both vitrectomy surgery and corticosteroid use. Risk factors for elevated IOP following vitreoretinal surgery have been reported to include the number of photocoagulations, the severity of postoperative vitreous haemorrhage, and the use of gas tamponade. ${ }^{8}$ Using 15 years of Medicare claims data, Stein et al reported glaucoma rates of $6 \%$ to $8 \%$ following PPV. ${ }^{2}$ Atchison and Pollack performed a retrospective comparison of post-PPV treatment with subconjunctival dexamethasone plus topical steroids in 146 patients versus subconjunctival triamcinolone without drops in 135 patients. They reported IOP elevations $\geq 10 \mathrm{~mm} \mathrm{Hg}$ occurring at rates of $14 \%$ and $20 \%$, respectively. ${ }^{4}$ The rates of clinically significant IOP elevation in this study, $7.4 \%$ in the ICD group 
and $11.1 \%$ in the topical corticosteroid group, were both within the previously reported ranges.

Cataract progression in phakic eyes was frequently observed in this group of patients and is a known side effect of both PPV $^{1}$ and steroid use. Other AEs were observed less frequently and were primarily those expected following intraocular surgery.

This is the first report of the use of this ICD formulation for treatment of inflammation following PPV and retinal surgery. Donnenfeld and Holland have reported on the safety and efficacy of the same formulation following cataract surgery. Their placebo-controlled trial enrolled 394 patients and reported nearly the same rate of complete ACC clearing (66\%) at POD 8 as was observed in this cohort. The finding of a statistically significant benefit of the ICD treatment out to POD 30 in their trial, versus only to day 7 in the current trial, is likely due to the active treatment of the control group with topical corticosteroids in the present study. ${ }^{9}$

The delivery of a corticosteroid, using a single administration after the completion of surgery, eliminates the potential for compliance problems that can compromise postoperative treatment outcomes when patients selfadminister eye drops. This formulation immediately begins treating intraocular inflammation without the need to penetrate the cornea. The $5 \mu \mathrm{L}$ droplet injected into the eye after surgery forms a surface tension-based sphere, and the drug is released into the eye as the droplet is absorbed. When the drug depot is fully absorbed, drug delivery stops. The concentration of drug delivered is highest on the day of application, and as the medication dissipates, the concentration in the anterior chamber should taper slowly at the same time as the need for anti-inflammatory therapy decreases. $^{9}$

The retrospective nature of this study, in addition to the modest sample size, are limitations. The comparison of real-world outcomes to a known standard of care, although using only one brand of topical corticosteroid, does provide useful information to clinicians. These data can provide the proof of concept for designing a randomised, prospective trial comparing ICD to topical postoperative treatments following PPV.

In this case-controlled retrospective study, dexamethasone drug-delivery suspension placed in the anterior chamber at the conclusion of vitreoretinal surgery was more effective in controlling inflammation than a standard corticosteroid eyedrop regimen. The nature of the AEs recorded was consistent with the profile expected following these posterior segment surgeries. Treatment of postoperative inflammation with this ICD suspension may offer clinical benefits to retinal surgeons and their patients.
Acknowledgements The author thanks Timothy Comstock for medical writing assistance.

Contributors DFK provided substantial contributions to the conception or design of the work; including the acquisition, analysis or interpretation of data for the work; and drafting the work or revising it critically for important intellectual content; and final approval of the version to be published; and agreement to be accountable for all aspects of the work in ensuring that questions related to the accuracy or integrity of any part of the work are appropriately investigated and resolved.

Funding This study was supported by an independent investigator grant from EyePoint Pharmaceuticals.

Competing interests EyePoint Pharmaceuticals—speaker, consultant, research grant support.

Patient and public involvement Patients and/or the public were not involved in the design, or conduct, or reporting or dissemination plans of this research.

Patient consent for publication Not required.

Provenance and peer review Not commissioned; externally peer reviewed.

Data availability statement Data are available upon reasonable request. All data relevant to the study are included in the article or uploaded as supplementary information. Deidentified participant data are available from the author upon request.

Open access This is an open access article distributed in accordance with the Creative Commons Attribution Non Commercial (CC BY-NC 4.0) license, which permits others to distribute, remix, adapt, build upon this work non-commercially, and license their derivative works on different terms, provided the original work is properly cited, appropriate credit is given, any changes made indicated, and the use is non-commercial. See: http://creativecommons.org/licenses/by-nc/4.0/.

ORCID iD

Daniel F Kiernan http://orcid.org/0000-0002-9447-8640

\section{REFERENCES}

1 Reddy RK, Lalezary M, Kim SJ, et al. Prospective retinal and optic nerve vitrectomy evaluation (prove) study: findings at 3 months. Clin Ophthalmol 2013;7:1761-9.

2 Stein JD, Zacks DN, Grossman D, et al. Adverse events after pars plana vitrectomy among Medicare beneficiaries. Arch Ophthalmol 2009;127:1656-63.

3 Agarwal A, Joshi D, Katoch D, et al. Application of laser flare photometry in the quantification of Blood-Aqueous barrier breakdown after Micro-incision vitrectomy. Ocul Immunol Inflamm 2019;27:651-7.

4 Atchison E, Pollack J. Rethinking routine use of steroid drops after surgery. retina specialist web site, 2019. Available: https://www.retinaspecialist.com/article/rethinking-routine-use-of-steroid-drops-aftersurgery [Accessed 25 Jan 2020].

5 Shorstein NH, Myers WG. Drop-free approaches for cataract surgery. Curr Opin Ophthalmol 2020;31:67-73.

6 Paccola L, Jorge R, Barbosa JC, et al. Anti-inflammatory efficacy of a single posterior subtenon injection of triamcinolone acetonide versus prednisolone acetate $1 \%$ eyedrops after pars plana vitrectomy. Acta Ophthalmol Scand 2007;85:603-8.

7 Yasuda K, Motohashi R, Kotake O, et al. Comparative effects of topical diclofenac and betamethasone on inflammation after vitrectomy and cataract surgery in various vitreoretinal diseases. $J$ Ocul Pharmacol Ther 2016;32:677-84.

8 Hasegawa Y, Okamoto F, Sugiura Y, et al. Intraocular pressure elevation after vitrectomy for various vitreoretinal disorders. Eur $J$ Ophthalmol 2014;24:235-41.

9 Donnenfeld E, Holland E. Dexamethasone intracameral drug-delivery suspension for inflammation associated with cataract surgery: a randomized, placebo-controlled, phase III trial. Ophthalmology 2018;125:799-806. 